\title{
Diagnosis of axial displacement in transformer windings using finite element analysis
}

\author{
Kamran Dawood $^{\mathrm{a}^{*}}$, Mehmet Aytaç Çınar ${ }^{\mathrm{b}}$ and Bora Alboyacı $^{\mathrm{c}}$ \\ ${ }^{a}$ Department of Electrical Engineering, İstanbul Technical University, İstanbul, Turkey \\ ${ }^{\mathrm{b}}$ Izmit Vocational School, Kocaeli University, Kartepe, Kocaeli, Turkey \\ ${ }^{\mathrm{c}}$ Department of Electrical Engineering, Kocaeli University, İzmit, Kocaeli, Turkey \\ *Corresponding author E-mail: kamransdaud@yahoo.com
}

\author{
Article Info \\ Keywords: Leakage Reactance, Finite \\ Element Analysis, Energy method, Axial \\ Displacement, Transformer Mechanical \\ strength. \\ 2010 AMS: 41 A46 \\ Received: 13 April 2018 \\ Accepted: 10 May 2018 \\ Available online: 27 May 2018
}

\begin{abstract}
Transformer is one of the main equipment in the power system and power quality of the power system mainly depends on the working of the power transformer. Leakage reactance is one of the main parameters of the transformer. The design of the transformer has a significant impact on the leakage reactance of the transformer. The mechanical strength of the transformer mainly depends on the leakage reactance of the transformer. This paper investigates the leakage reactance of the transformer in normal conditions and during the axial displacement of the high voltage and low voltage windings using finite element analysis. Normal results of finite element analysis method are also compared with the experimental short-circuit test. Results show that leakage reactance of the transformer exponentially proportional to the displacement of the windings. It is observed that with the axial displacement of the $6 \%$ of the winding, leakage reactance increased by $10 \%$. Results also show that effect of the axial displacement in high voltage and low voltage winding is almost same.
\end{abstract}

\section{Nomenclature}

$\begin{array}{ll}L V & \text { Low Voltage } \\ H V & \text { High Voltage } \\ f & \text { Frequency } \\ I_{S} & \text { Rated secondary current } \\ V_{S} & \text { Rated secondary voltage } \\ W_{M} & \text { Magnetic field energy } \\ H & \text { Magnetic field strength } \\ \mu & \text { Permeability } \\ B & \text { Magnetic flux density } \\ A & \text { Magnetic vector field potential } \\ J & \text { Current density } \\ Z_{b} & \text { Base impedance } \\ L & \text { Inductance } \\ F E M & \text { Finite element method }\end{array}$




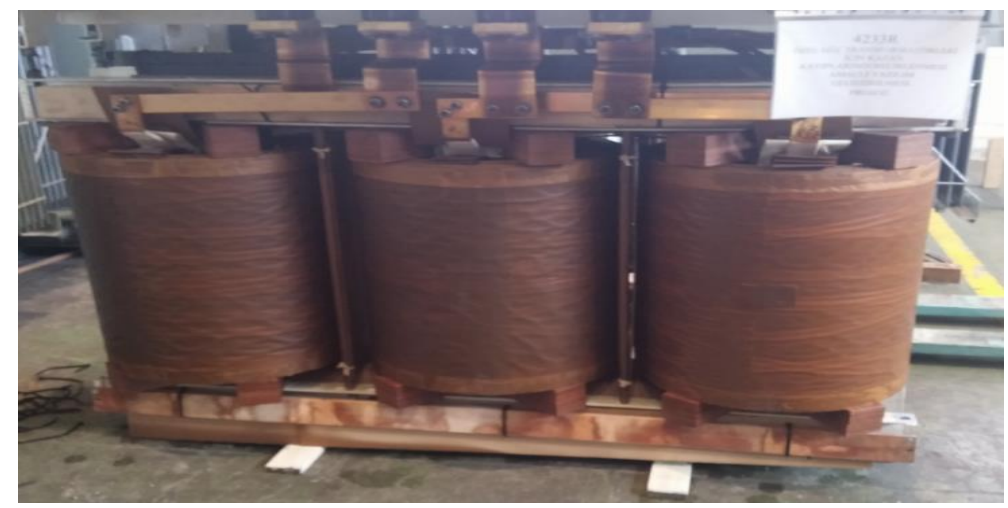

Figure 3.1: $34.5 / 4 \mathrm{kv} 1250 \mathrm{kVA}$ tested Transformer

\section{Introduction}

Transformers are most expensive apparatus in a power network; reliability and stability of the transformer mainly depend on the leakage reactance of the transformer [1]. Efficiency and the voltage drop in a transformer on load are chiefly affected by its leakage reactance, which must be kept as low as design, and manufacturing techniques would permit. Transformers are usually expected to work for more than 30 years [2] and during this period many different mechanical defects occur in transformers and damage level of the transformer increased with the time duration if the mechanical defect is not removed in the earliest stage. Many techniques are being used for the diagnostic techniques to mechanical defects detection. The most common diagnostic technique for the detection of the mechanical fault is the calculation of the leakage reactance and short circuit impedance [3]. In past, estimation of the flux in the different parts of the transformer was the most common used method for the calculation of the leakage reactance [4]. However, nowadays finite element analysis is one of the most common used technique for the calculation of the transformer [5]-[6]. The main drawback of FEM is that the accurate boundary conditions are very difficult to define [7]-[8]. Several studies have been conducted on the deformation of the transformer windings [9][10]-, but the effects of the displacement of the transformer windings are not highlighted that much. Even with the small displacement in transformer windings can increase leakage reactance and electromagnetic forces, which may cause heavy damage to the transformer. There are many available analytical methods for the calculations of the leakage reactance, however; it is not applicable when windings are displaced whether due to the transportation of the transformer or due to the mechanical fault in the transformer. In this study, short circuit test, transient analysis, magnetostatic analysis, and post-processing were performed to study the performance characteristics of the transformer during normal and axial displacement conditions. 3-dimensional transformer model was used in the transient and magnetostatic analysis to determine the magnetic energy and flux distribution in the transformer. In post-processing leakage reactance is calculated from obtained magnetic energy.

\section{Analyzed transformer}

In this study $1250 \mathrm{kVA}$, three-phase distribution transformer is used. M5 grain oriented silicon steel was used for the manufacturing of the transformer core. Main parameters and figure of the used transformer is given in Table 1 and figure 3.1 respectively.

\begin{tabular}{|l|l|c|}
\hline \multirow{5}{*}{ Ratings } & Capacity (MVA) & 1.25 \\
& High Voltage (kV) & 34.5 \\
& Low Voltage (kV) & 0.4 \\
& HV Current (A) & 12.08 \\
& LV Current (A) & 1804.37 \\
& Frequency (Hz) & 50 \\
\hline \multirow{3}{*}{ Core } & Material & M5 \\
\hline \multirow{2}{*}{ Windings } & Flux Density & 1.53 \\
& Material & Aluminum \\
& HV Turns & 2390 \\
& LV turns & 16 \\
\hline
\end{tabular}

Table 1: Transformer Data

B-H, B-P and Magnetization Curves of the core material of the studied transformer are shown in figure-2, 3 and 4 respectively.

\section{Finite element analysis}

The integral and differential equation can be solved by using FEM analysis [11]. In electrical engineering, FEM is most commonly used for the magnetostatic analysis, electromagnetic analysis and to determine the thermal characters and conductivity [12]. Reactance can be calculated accurately by using numerical method like FEM [13]. Due to the improvement in the computational techniques and modelling of the complex structured transformers become easier in FEM and effects of the different parameters on the transformer can be evaluated easily and accurately. The effects of the displacement in the transformer windings can be evaluated by using FEM. Geometry details of analysed transformer are given in Figure 4.1. 


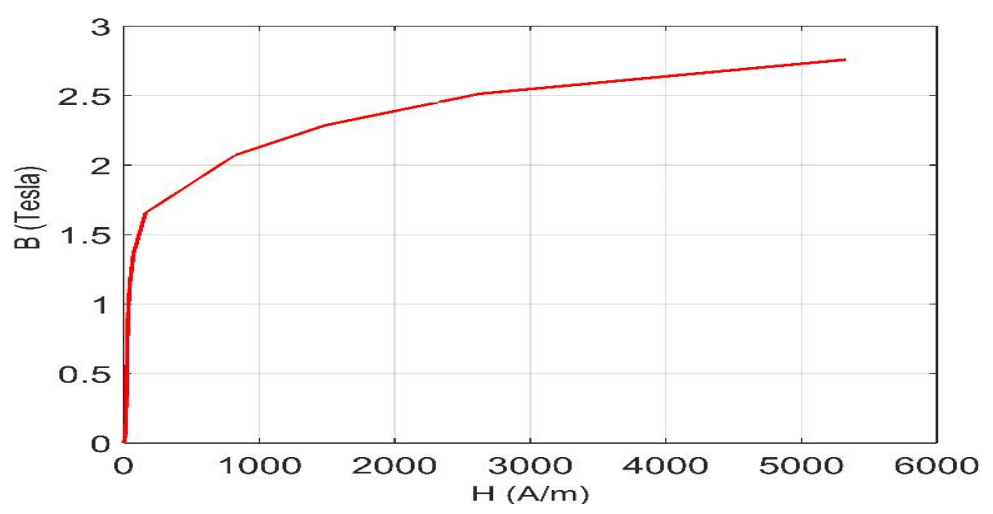

Figure 3.2: B-H curve of the Transformer

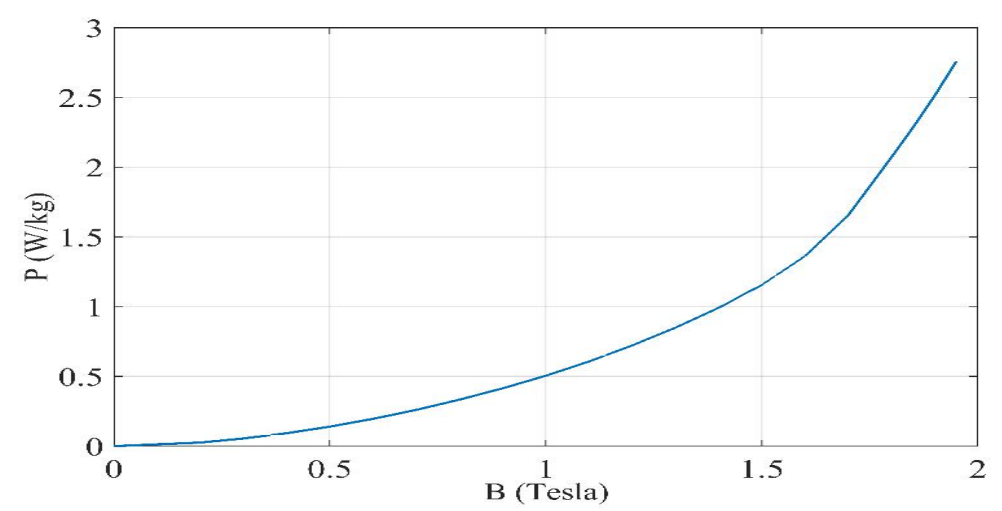

Figure 3.3: B-P curve of the Transformer

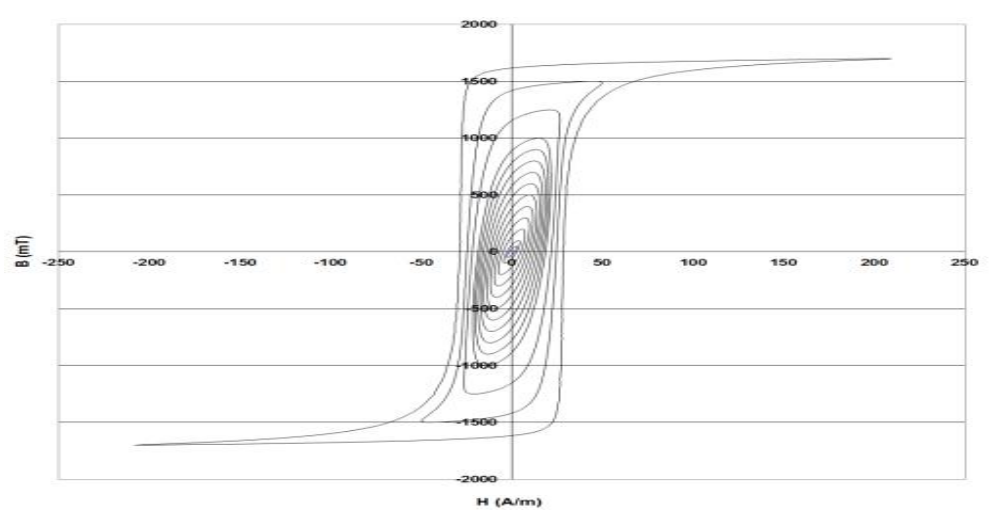

Figure 3.4: Magnetization Curves of the core material

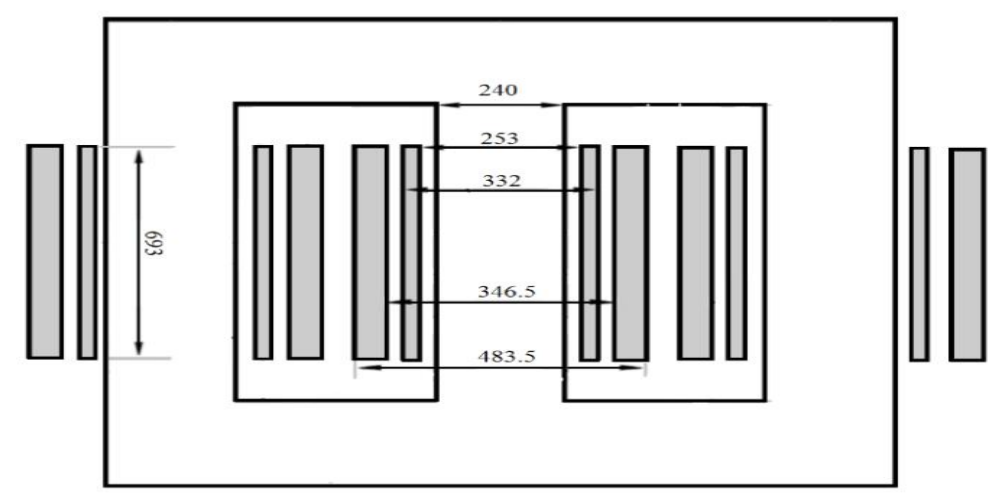

Figure 4.1: Geometry details of Analyzed Transformer 


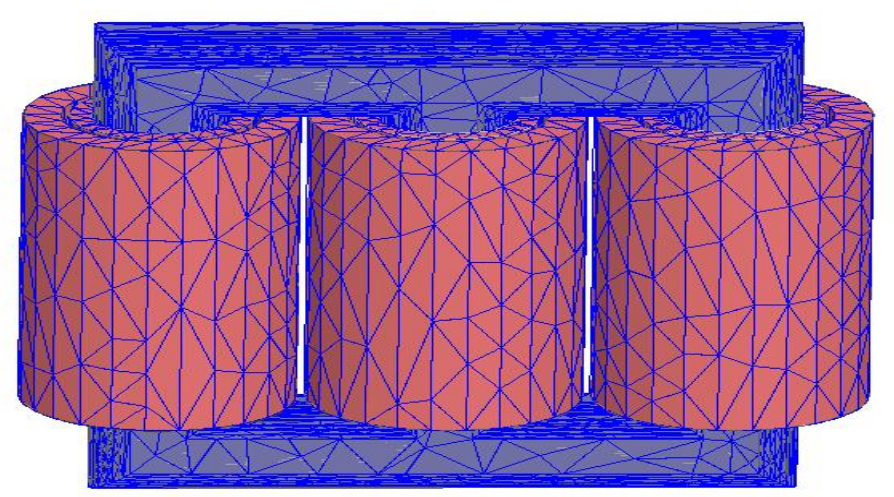

Figure 4.2: 3D Mesh operation of Studied Transformer.

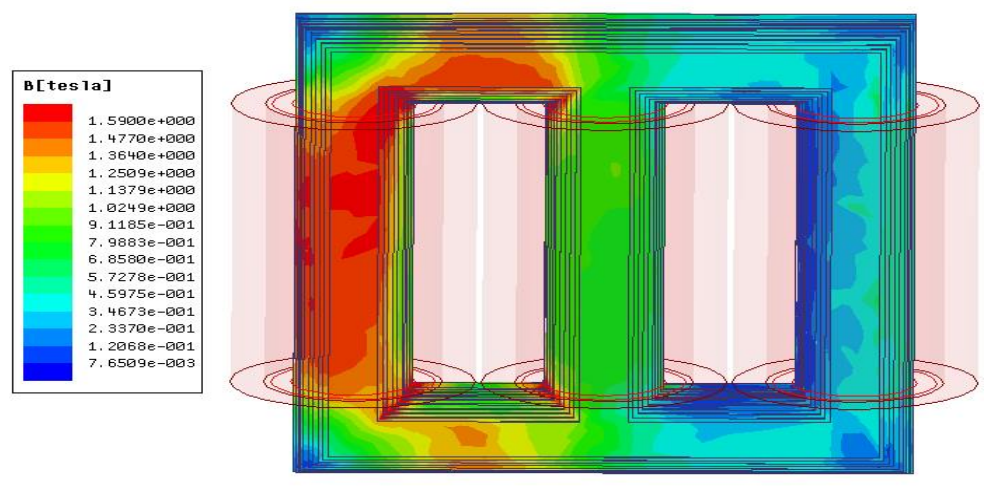

Figure 4.3: Magnetic flux distribution

3-D transformer model under mesh operation is shown in Figure 4.2, the number of the mesh generated in this model is 43146 elements. Figure 4.3 is showing magnetic flux distribution in the core of the transformer.

Magnetic energy is obtained from Ansys Maxwell FEM software. In the post-processing, obtained energy is converted into the inductance using equation (4.1) [14].

$$
L=\frac{2 W_{m}}{I^{2}}
$$

Total magnetic field energy of the magnetic field in each part in a volume can be calculated as by using equation (4.2)

$$
W_{m}=\int_{V} \frac{1}{2} B H d v
$$

where $H=\frac{B}{\mu}$. Equation (4.2) can be rewritten as

$$
W_{m}=\frac{1}{2 \mu} \int_{V} B^{2} d v
$$

From equation (4.1) and (4.2)

$$
L=\frac{2 W_{m}}{I^{2}}=W_{m}=\frac{1}{I^{2}} \int_{V} B H d v
$$

Another method for the calculation of the magnetic energy is by finding product of the magnetic vector potential and current density in volume

$$
W_{m}=\frac{1}{2} \int_{V} A J d v
$$

From equation (4.1) and (4.5)

$$
L=\frac{2 W_{m}}{I^{2}}=\frac{1}{I^{2}} \int_{V} A J d v
$$



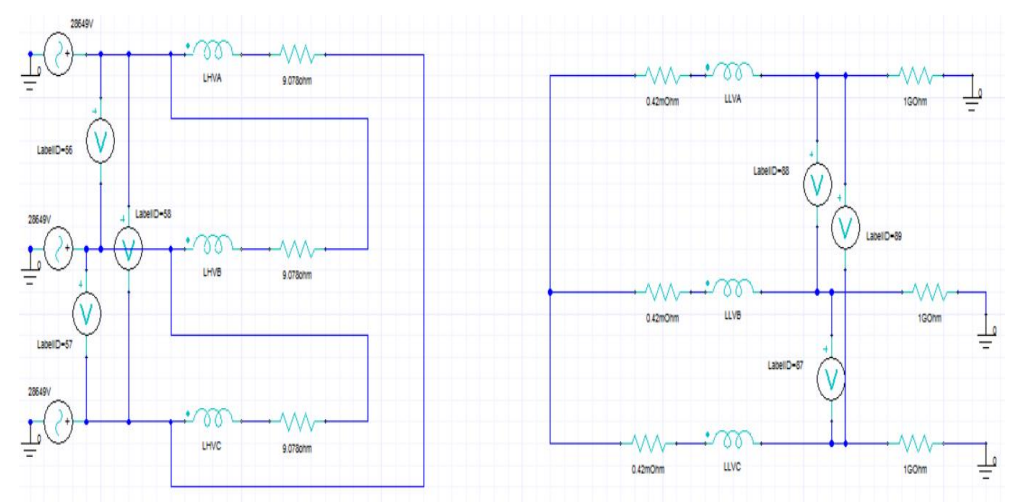

Figure 4.4: External Excitation Circuit of Three-phase Transformer.

The stored magnetic energy in the window space in the 2-D magnetic field can be calculated by using equation (4.7) and equation (4.8) [14]-[15].

$$
\begin{aligned}
& W_{m}=\frac{1}{2} t \iint B H d x d y \\
& W_{m}=\frac{1}{2} t \iint J A d x d y
\end{aligned}
$$

The leakage reactance of the transformer is calculated by using equation (4.9).

$$
X=\frac{2 \pi f L}{Z_{b}} \times 100
$$

The base impedance of the transformer can be calculated by using equation.

$$
Z_{b}=\frac{k V^{2}(H V \quad \text { side })}{M V A}
$$

External excitation circuit of the transformer using FEM is shown in Figure 5.1.

\section{FEM and short-circuit test results}

ANSYS MAXWELL® is used for the calculation of the leakage reactance. For normal conditions results of the finite element analysis are compared with the short-circuit test of the transformer. Magneto-static analysis, transient analysis, and post-processing solutions are used for the determination of the leakage reactance. Calculated experimental and finite element analysis leakage reactance is given in Table 2. For short-circuit test, voltage is applied to the HV windings and LV windings are short circuited in order to pass a rated current in HV and LV windings. The test is performed according to the IEC 60076-1. Measurement of the leakage reactance is performed quickly so that the temperature rises do not affect the measured results.

\begin{tabular}{|c|c|c|}
\hline Short-circuit Test & FEM Method & Analytical Method \\
\hline 6.15 & 6.17 & 6.15 \\
\hline
\end{tabular}

Table 2: Calculation of leakage reactance during normal conditions

Table 3 is showing the leakage reactance during the axial displacement of the winding. In finite element analysis, at a time one winding is displaced and second remains constant. Results show that effect of axial displacement of the LV and HV windings is almost same.

The relationship between the leakage reactance and winding displacement is shown in figure-9. Results show that the leakage reactance is directly proportional to the displacement of the transformer windings. The axial height of the windings was $693 \mathrm{~mm}$ and with the displacement of the $20 \mathrm{~mm}$ leakage reactance increase by $3 \%$ and with the displacement of $40 \mathrm{~mm}$ leakage reactance increased by $12.5 \%$.

\section{Conclusion}

This paper investigates the effect of the axial displacements of the windings on the leakage reactance of the transformer. Finite element method is used to determine the leakage reactance of the transformer and FEM results are validated with the short-circuit tests of the transformer. Results show that finite element analysis technique is the highly efficient technique to determine the leakage reactance of the transformer during the normal and displaced conditions. This method can help the transformer manufacturers in the designing stage of the transformer and during the axial displacement of the HV or LV winding in the transformer. 


\begin{tabular}{|c|c|c|c|}
\hline Displacement $(\mathrm{cm})$ & Leakage Reactance & Displacement $(\mathrm{cm})$ & Leakage Reactance \\
\hline 0.2 & 6.175 & 2.2 & 6.41 \\
0.4 & 6.179 & 2.4 & 6.45 \\
0.6 & 6.19 & 2.6 & 6.5 \\
0.8 & 6.2 & 2.8 & 6.55 \\
1.0 & 6.21 & 3.0 & 6.61 \\
1.2 & 6.24 & 3.2 & 6.67 \\
1.4 & 6.258 & 3.4 & 6.73 \\
1.6 & 6.29 & 3.6 & 6.8 \\
1.8 & 6.33 & 3.8 & 6.87 \\
2.0 & 6.37 & 4.0 & 6.945 \\
\hline
\end{tabular}

Table 3: Calculation of leakage reactance during normal conditions

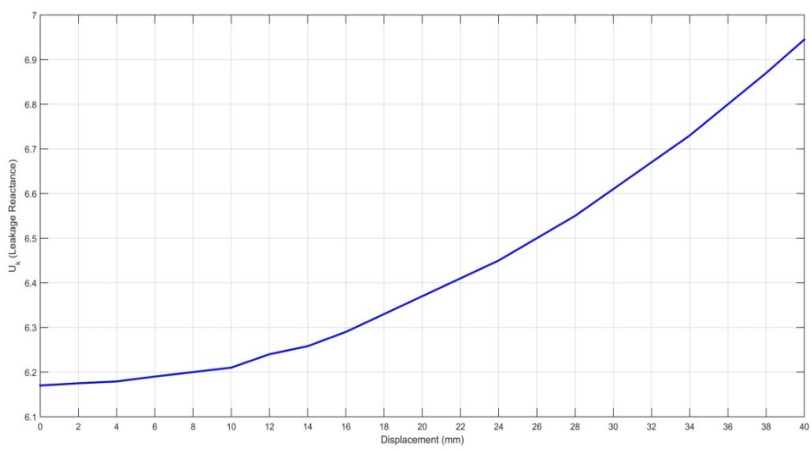

Figure 5.1: Relationship between displacement and leakage reactance

\section{Acknowledgement}

The authors would like to express their deepest gratitude to the Sonmez Transformer Company (STS) of Turkey for the technical and financial support and providing the practical data of the transformer.

\section{References}

[1] Dawood K., Alboyaci B., Cinar M.A., and Sonmez O., "Modelling and Analysis of Transformer using Numerical and Analytical Methods", 18th International Symposium on Electromagnetic Fields ISEF 2017, Lodz, Poland, 14-16 Sept. 2017.

[2] Heathcote M., J \& P Transformer Book, Thirteenth Edition, Elsevier Ltd., 2007.

[3] Secue J.R. and Mombello E., "Sweep frequency response analysis (SFRA) for the assessment of winding displacements and deformation in power transformers" Elsevier, Electric Power System Research, Vol. 78, pp. 1119-1128, 2008.

[4] Karsai K., Kerenyi D. and Kiss L., Large Power Transformers, Hungary, Elsevier, 1987.

[5] Leon F. D., Semlyen A., "Efficient Calculation of Elementary Parameters of Transformer", IEEE Transactions on Power Delivery, Vol. 7, pp. 376-383, 1992.

[6] Prieto R., Garsia O., and Aluo P. "Study of 3-D Magnetic Components by Means of Double 2-D Methodology", IEEE Transactions. on Industrial Electronics, Vol. 50(1), pp. 183-192, 2003

[7] Tomczuk B., "Three-Dimensional Leakage Reactance Calculation and Magnetic Field Analysis for Unbounded Problems", IEEE Transaction On Magnetic, Vol 28(4), pp. 1935-1940, 1992.

[8] Rao S., The Finite Element Method in Engineering. Bytterworth-Heinmann, 1999, pp 45-85.

[9] Baobin L., and Wei Z. Analysis and Online Testing of the Transformer Winding Deformation. Procedia Engineering Elsevier, Vol. 29, pp. 306-310, 2012.

[10] Karimifard P., and Gharehpetian G.B., "A new algorithm for localization of radial deformation and determination of deformation extent in transformer windings", Electric Power Systems Research, Vol. 78(10), 2008: 1701-1711.

[11] Rao S. S., The finite element method in engineering: Elsevier ; 2010

[12] Dawood K., Cinar M.A., Alboyacı B. and Sonmez O., "Efficient Finite Element Models for Calculation of the No-load Losses of the Transformer", International Journal of Engineering \& Applied Sciences, Vol. 9(3), pp.11-21, 2017.

[13] Santhi S., Jayashankar V., " Continual assessment of winding deformation during a short circuit test", IEEJ Transactions on Power and Energy, Vol. 126(7), pp.712-713, 2006.

[14] Dawood K., Alboyaci B., Cinar M.A., Sonmez O., "A new method for the calculation of leakage reactance in power transformers", Journal of Electrical Engineering \& Technology, Vol. 12(5), pp. 1883-1890, 2017.

[15] Saadat J. A., Karim A. "The Study of Magnetic Flux Shunts Effects on the Leakage Reactance of Transformers via FEM", Majlesi Journal of Electrical Engineering, Vol. 4(3), 2010. 